\title{
VERSIONS, DUBS AND RIDDIMS: \\ Dub and the Transient Dynamics of Jamaican Music
}

\author{
$\bullet$ Feature Article $\longrightarrow$ \\ THOMAS VENDRYES \\ Ecole Normale Supérieure de Cachan (France)
}

\begin{abstract}
Dub emerged in Jamaica in the early 1970s, and, for a decade, it became a prolific and intensely innovative dimension of Jamaican popular music. Yet, during the mid1980s, while dub flourished at the international level, influencing popular music in general, the genre of dub declined in popularity in Jamaica. How could this musical innovation, so evidently associated with Jamaica, expand and develop internationally while at the same time decline in Jamaica itself? In this paper, I explore the modalities and evolution of Jamaican music production and consumption. Through a description of the Jamaican music industry context, with reference to individual artists' paths and a summary of Jamaican dub production, I show that even as the Jamaican music milieu was highly favorable to the emergence of dub, dub proliferated as a genre only by developing ties to a diaspora of international audiences and practitioners.
\end{abstract}

KEYWORDS: production studies, Jamaican popular music, history of dub, audio-engineer, riddim, performance mixing

Thomas Vendryes is Associate Professor at the Department of Social Sciences of the École Normale Supérieure de Cachan and researcher at the Centre d'Économie de la Sorbonne (France). His research focuses on socio-economic change in developing countries.

Dancecult: Journal of Electronic Dance Music Culture 7(2): 5-24

ISSN 1947-5403 @2015 Dancecult http://dj.dancecult.net

http://dx.doi.org/10.12801/1947-5403.2015.07.02.01

dasncecult 
"What will happen to dub in 1983 ?"

-Scientist Encounters Pac-man LP (back cover)

Dub is Eternal

-The 420 DubKraft Anthology

\section{INTRODUCTION}

Emerging from the practice of versioning (i.e. multiple interpretations of a given instrumental track) that sprang up at the close of the 1960s, dub became a psychedelic and prominent dimension of roots reggae that came to dominate the 1970s. A couple of years after the release of a handful of pioneer dub albums around 1973, the B-sides of Jamaican singles were almost universally devoted to the dub re-interpretation of the tune pressed on the A-side. Dub artists such as King Tubby, Lee Perry, Errol Thompson, Scientist and Augustus Pablo rose to fame, with a few receiving international recognition. By the late 1970s, dub had become a fully grown-up genre, with specific production techniques and aesthetics, a pantheon of "Kings" and a wide audience (Barrow and Dalton 2004: 215, 230).

It was in the late 1970s that the dub phenomenon spread out of Jamaica. By the 1980s, a series of producers at least partially specialized in dub had become active in the UK (Dennis Bovell, Adrian Sherwood, Mad Professor) and in the US (most notably Brad Osborne and Lloyd "Bullwackie" Barnes) (Sullivan 2014: 77-96). The dub genre was nurtured and expanded internationally by a community of dedicated groups and artists, from France (Zenzile) to Japan (Dry \& Heavy), and from Germany (Rhythm \& Sound) to Canada (Dubmatix). Maybe even more importantly, the dub techniques and aesthetics developed in Jamaica - and especially the concept and practice of the remix - are considered as having a significant impact on the way music is created and produced in a wide array of genres, from punk to hip-hop and dance music (Howard 2004: 231).

However, at the same time that dub disseminated outside of Jamaica, and even outside of the boundaries of Jamaican music, it lost ground in its home country (Barrow and Dalton 2004: 215). Some dub artists left the country (Lee Scratch Perry, Scientist) while others turned to new genres such as dancehall (King Jammy, King Tubby), leaving only a handful to maintain dub alive in Jamaica, though mostly as a side activity (Sly \& Robbie). Herein lies the paradoxical aspects of the birth and development of dub as a genre: whereas dub was born in Jamaica, with a set of aesthetic and technical characteristics that are specific-if not unique-to Jamaican popular music, after a decade or so, dub almost disappeared in its native land, while propagating out of Jamaica's national and musical frontiers. The aim here is to show that if dub was born in Jamaica it is because it is deeply rooted, as a genre, in the particular ways Jamaican music is consumed and produced. But the very forces and dynamics that allowed dub to emerge eventually surpassed it, leaving dub as a transient byproduct of Jamaican music's structural evolution, nurtured and developed, then, in other contexts. 
This paper will first briefly recall the birth and history of dub, then identify the reasons why this particular genre emerged in Jamaica in the 1970s, and, in the last section, discuss why its production shifted from Jamaica to an international milieu.

\section{A Brief History Of A jamaican Music Progeny: The Birth, Growth And Departure Of Dub}

\section{Toward The Birth Of Dub}

Motta's studio foundation in 1951 (Hitchins 2014: 14) marked the beginning of music recording in Jamaica, which sprouted out of two roots (O'Brien Chang and Chen 1998: 10-18; Barrow and Dalton 2004: 3-11). The first such "root" came from colonial history, in the inheritance of African, Christian and Caribbean mixed musical forms (Pocomania, Kumina, Revival Zion), and of European settlers' dances (such as the quadrille or mazurka). It eventually gave birth to mento, the first musical genre specific to Jamaica. The second root of Jamaican music was the US African-American influence in the 1940s and 1950s, especially rhythm and blues as well as (big band) jazz, which were extremely popular among Jamaica's then-emerging urban audience (O'Brien Chang and Chen 1998: 20-1; Bradley 2001: 15; Barrow and Dalton 2004: 17-18). In the 1950s and early 1960s, both mento and what came to be called "Jamaican boogie" were recorded in Kingston's first studios (Hitchins 2014: 7).

A crucial, and original, trait of Jamaican music, which has remained characteristic ever since, was that the main outlet for music, the primary place of music consumption, was the dance hall, where the prime actors were the "sound systems" (Stolzoff 2000). Their centrality has had four important consequences for Jamaican music and its evolution. First, the essential musical objective was dance. Second, the huge power of sound systems gave them the capacity to reproduce a wide range of sonic detail (Hitchins 2014: 35-6), especially in low-frequencies, which had become a signature of Jamaican musical production (Hitchins 2014: 81-5; and as underscored by the very title of Bradley's influential book about reggae, Bass Culture [2001]). Jamaican music has then been designed to be felt as much as it is heard, to generate what Henriques calls "sonic dominance", where "the bass line beats on our chest, vibrating the flesh, playing on the bone and resonating the genitals" (2003: 452). Third, Jamaican music production was driven by fierce competition between sound system operators, in constant search of new, original and specific recordings, dub plates (i.e. blanklabels, specials, acetates), that would allow them to "dominate" competitors (O'Brien Chang and Chen 1998: 19-24). The fourth and final consequence is that Jamaican practices of the sound system have given a prominent role to DJs, who have been, since the founding figures of Count Machukie and then U-Roy (Bradley 2001: 292-298), in charge of introducing, commenting and "toasting" on the music played by the selecta. ${ }^{1}$

It was in the early 1960s, from these two musical roots, the colonial and AfricanAmerican, and within the context of the dance hall, structured by sound systems, that ska 
emerged, "the first music that the rest of the world associated exclusively with Jamaica" (Barrow and Dalton 2004: 3). With its characteristic horn lines, "the ska beat was fast, appropriate for dancing, and emphasized offbeat accents that propelled the music forward" (Moskowitz 2006: 271). Ska was soon to be replaced by the "slower, more refined and, most of all, cooler" rocksteady (Barrow and Dalton 2004: 55). After a couple of years of gestation, rocksteady gave birth to reggae, with the term appearing on the Maytals' "Do The Reggay" in 1968 (Barrow and Dalton 2004: 87). Since then, reggae has gained international recognition, listened to by audiences and played by bands on all continents as well as receiving its own Grammy category in 1985. Whereas reggae is an "umbrella term" that "went on to encompass a wide variety of styles" (Moskowitz 2006: 253), some general and characteristic musical traits can be identified, mainly the prominence of the rhythm section, the importance of low-frequencies (especially bass) and syncopation due to emphasis on the offbeats and afterbeats (O'Brien Chang and Chen 1998: 43). ${ }^{2}$ In the late 1960 s through early 1970s, the aesthetics as well as the general context of Jamaican music had become well established, and ready for the sprouting of versions and their development into dubs.

\section{VERSIONS AND DUBS}

The release of the first version ${ }^{3}$ in 1967 is one of the most famous and referential turning points in the history of Jamaican music (Bradley 2001: 312; Barrow and Dalton 2004: 216-7; Veal 2007: 52). One evening in 1967, Rudolph "Ruddy" Redwood, operator of the Supreme Ruler of Sound sound system, went, as usual, to Duke Reid's Treasure Isle recording studio to get some "specials" from Reid's audio engineer, Byron Smith. However, "as he ran through the tapes of [The Paragons'] "On The Beach", Byron Smith inadvertently left the vocal track off" (Barrow and Dalton 2004: 216). This instrumental version became a huge success at Ruddy's next dance. Immediately after this "spine-tingling moment" (Bradley 2001: 312), versions became the new craze with Jamaican music audiences and producers. In a couple of years, the B-sides of Jamaican singles almost universally provided a version of the vocal track pressed on the A-side. These first versions constituted recordings where the vocal track has been simply removed, muted from the original song, and sometimes replaced by an instrumental solo (Barrow and Dalton 2004: 218).

Eventually, the rhythm tracks presented by versions came to be interpreted and worked on, giving birth to dub. "Voo-doo", ${ }^{4}$ by The Hippy Boys (1971) is generally considered as the first dub track (Barrow and Dalton 2004: 219). Dub versions of an original recording did not only mute and remove the vocals, they manipulated, de-constructed and re-constructed the left-over tracks, with the addition of various sound and audio effects, in particular tape delay, reverb and echo (Veal 2007: 64-76). An illustrative example of the difference between versions and dubs is the comparison of the version of Horace Andy's "Skylarking" produced by Coxsone Dodd in 1972, with the dub mixed by King Tubby for the same song released by Bunny Lee a few years later. ${ }^{5}$ The more sophisticated dubs progressively replaced 
versions on B-sides, while in the early 1970s a handful of "first dub album ever" candidates were released: Prince Buster's The Message Dubwise, Herman Chin-Loy's Aquarius Dub, Java Java Java Java by the Chin Brothers and Errol Thompson, and finally The Upsetters' Blackboard Jungle Dub, mixed by Lee "Scratch" Perry and King Tubby. In the second half of the 1970s, dub practically became the reverse side of reggae: B-sides of Jamaican singles were covered by the dub versions of A-side recordings, and the number of dub albums increased exponentially. A new generation of artists-producers, musicians, audio-engineers-came to the forefront of this emerging scene, as shown in Table $1 .{ }^{6}$

By the end of the 1970s, dub was not just a marginal subgenre of mainstream reggae, it was one of its key dimensions, with a prominent aesthetic influence. For example, King Tubby, a leading audio-engineer, producer and sound system operator of the 1970s and 1980 s, one of the "founding fathers" of dub, became much sought-after by producers to mix dub B-sides (Bradley 2001: 323). Eventually, dub was perceived not as a secondary interpretation, a B-side, but rose to its full independence as an A-side. In 1975, the single "Baby I Love You So" (produced by Augustus Pablo, vocals by Jacob Miller) was released in the UK with the dub version by King Tubby (the classical "King Tubby Meets Rockers Uptown") on the A-side (Bradley 2001: 323). A year later, Lee "Scratch" Perry released what is "often considered one of the defining statements of the genre" (Veal 2007: 158), the Super Ape album (1976). What is crucial here is that some of the album's tracks-including the title song "Super Ape"-were not direct reinterpretations of existing materials. The dubs were not to be heard with an "original" track in mind; they were not versions anymore. From B-side versions, dub finally settled as a genre into full A-side status (Sullivan 2014: 48).

\section{The Eventual Decline Of Dub In Jamaica And The Dub Diaspora}

Dub: born in the early 1970s, grown-up by the end of decade and gone by the mid-1980s. As Veal writes: "the early 1980s were also the last years of dub as a contemporary musical movement in Jamaica" (2007: 188). The stream of dub albums dried up, as can be seen in the Discogs database: 152 dub albums were released in Jamaica during the 1970s, 74 in the 1980s, 36 in the 1990s and a dozen since $2000{ }^{7}$ Even if this information may not be exhaustive, it confirms a well-acknowledged trend.

This impression is confirmed by a quick examination of the careers of the main actors of the Jamaican dub scene. Table 1 presents the dub pioneers of the very early 1970s: Errol Thompson, Clive Chin, Herman Chin-Loy, Augustus Pablo, Keith Hudson, Bunny Lee, King Tubby and Lee Perry. They were followed, in the mid-1970s, by a second generation of dub artists, such as Jammy, Scientist (both disciples of King Tubby), Sly \& Robbie and the late-comer Peter Chemist, who also trained at Tubby's studio. The striking observation is that for almost all of them, the production of dubs became less prolific by the mid-1980s. Three trajectories are visible. Most simply left the music industry at that time (Clive Chin, Errol Thompson, Herman Chin-Loy, Keith Hudson, Sylvan Morris, Dub Specialist). Others remained active, but shifted their musical production away from dub and toward the new 


\section{digital sounds of dancehall (Bunny Lee, King Tubby, Jammy, Sly \& Robbie). Only Lee Perry} and Scientist have kept issuing dubs as their core musical activity-but outside of Jamaica. So by the end of the 1980s, dub was clearly no longer a "contemporary musical movement in Jamaica" (Veal 2007: 188).

\begin{tabular}{|c|c|c|c|c|c|}
\hline $\begin{array}{l}\text { Artist } \\
\text { Audio Engineer } \\
\text { Producer }\end{array}$ & $\begin{array}{l}\text { Beginning } \\
\text { of musical } \\
\text { activity }\end{array}$ & $\begin{array}{l}\text { Beginning } \\
\text { of dub } \\
\text { production }\end{array}$ & $\begin{array}{l}\text { End } \\
\text { of dub } \\
\text { production } \\
\text { in Jamaica }\end{array}$ & $\begin{array}{l}\text { End of } \\
\text { musical } \\
\text { activity }\end{array}$ & Notes \\
\hline Augustus Pablo & c. 1971 & c. 1971 & c. 1993 & 1999 & $\begin{array}{l}\text { Pablo's dub production slowed in the 1980s, and almost } \\
\text { stopped by the mid-1990s. Pablo passed away in } 1999 \text {. }\end{array}$ \\
\hline $\begin{array}{l}\text { Bunny "Striker" } \\
\text { Lee }\end{array}$ & mid-1960s & early 1970 s & mid-1980s & cont. & $\begin{array}{l}\text { A very influential producer of the } 1970 \text { s, Lee played a key } \\
\text { role in the development of dub, with King Tubby and } \\
\text { Jammy. }\end{array}$ \\
\hline Clive Chin & early 1970 s & early 1970 s & mid-1970s & mid-1970s & $\begin{array}{l}\text { C. Chin was mainly active as a producer in the early 1970s. } \\
\text { He left the music industry and Jamaica in the mid-1970s. }\end{array}$ \\
\hline Dub Specialist & c. 1974 & c. 1974 & c. 1980 & c. 1980 & $\begin{array}{l}\text { Dub Specialist is the generic name under which a series of } \\
\text { dub albums were issued by producer C. Dodd, before he } \\
\text { moved to New York. }\end{array}$ \\
\hline $\begin{array}{l}\text { Errol "ET" } \\
\text { Thompson }\end{array}$ & late 1960s & early $1970 \mathrm{~s}$ & $\begin{array}{l}\text { early } \\
1980 \text { s }\end{array}$ & 2004 & $\begin{array}{l}\text { "ET" is mainly famous for his work with producer Joe } \\
\text { Gibbs (African Dub All-Mighty series) in the 1970s-early } \\
\text { 1980s. He passed away in 2004. }\end{array}$ \\
\hline $\begin{array}{l}\text { Herman Chin- } \\
\text { Loy }\end{array}$ & c. 1970 & c. 1970 & mid-1970s & mid-1970s & $\begin{array}{l}\text { One of the very first pioneers of dub with the album } \\
\text { Aquarius Dub (1973), Herman Chin-Loy had limited activity } \\
\text { after } 1975 .\end{array}$ \\
\hline Keith Hudson & $\begin{array}{l}\text { end of } \\
1960 \text { s }\end{array}$ & c. 1974 & c. 1974 & 1984 & $\begin{array}{l}\text { After a brief career in Jamaica, including the release of the } \\
\text { influential Pick ADub in 1974, K. Hudson emigrated to the } \\
\text { UK, and then US. }\end{array}$ \\
\hline King Tubby & c. 1970 & c. 1970 & mid-1980s & 1989 & $\begin{array}{l}\text { A pivotal figure of the genre, King Tubby's dub releases } \\
\text { slowed after the mid-1980s. He was shot dead in } 1989 .\end{array}$ \\
\hline $\begin{array}{l}\text { Lee "Scratch" } \\
\text { Perry }\end{array}$ & early 1960s & c. 1970 & $\begin{array}{l}\text { early } \\
1980 \text { s }\end{array}$ & cont. & $\begin{array}{l}\text { A pioneer and eminent figure of Jamaican dub, Lee Perry } \\
\text { destroyed his own studio and left Jamaica in the early 1980s. }\end{array}$ \\
\hline $\begin{array}{l}\text { Lynford } \\
\text { "Andy Capp" } \\
\text { Anderson } \\
\end{array}$ & c. 1960 & c. 1970 & late $1970 \mathrm{~s}$ & late 1970s & $\begin{array}{l}\text { Andy Capp was one of the most prolific audio-engineer in } \\
\text { the early years of versions, making a key contribution to } \\
\text { mixing techniques. }\end{array}$ \\
\hline Peter Chemist & early 1980 s & early 1980 s & late $1980 \mathrm{~s}$ & cont. & $\begin{array}{l}\text { A late comer in Jamaican dub, Peter Chemist was active as an } \\
\text { audio engineer mixing dubs in the mid-1980s. }\end{array}$ \\
\hline $\begin{array}{l}\text { Prince/King } \\
\text { Jammy }\end{array}$ & c. 1976 & c. 1976 & late $1980 \mathrm{~s}$ & cont. & $\begin{array}{l}\text { Starting at Tubby's studio in the mid-1970s, Jammy has been } \\
\text { releasing dubs ever since, even if only marginally after the } \\
\text { mid-1980s. }\end{array}$ \\
\hline Scientist & c. 1975 & c. 1975 & c 1985 & cont. & $\begin{array}{l}\text { A disciple of King Tubby in the mid-1970s, Scientist left } \\
\text { Jamaica in 1985, and continues to release dubs from the US. }\end{array}$ \\
\hline Sly \& Robbie & mid-1970s & mid-1970s & mid-1980s & cont. & $\begin{array}{l}\text { A very influential rhythmic section, Sly \& Robbie actively } \\
\text { released dubs up to the mid-1980s, but only occasionally } \\
\text { afterward. }\end{array}$ \\
\hline Sylvan Morris & mid-1960s & early 1970 s & late $1970 \mathrm{~s}$ & late $1980 \mathrm{~s}$ & $\begin{array}{l}\text { Morris is an important yet under-credited audio-engineer, } \\
\text { who most notably mixed dubs for Coxsone Dodd, Harry J } \\
\text { and Augustus Pablo. }\end{array}$ \\
\hline
\end{tabular}

TABLE 1. AN OVERVIEW OF JAMAICAN DUB ARTISTS 
It does not mean that dubs suddenly disappeared from the Jamaican musical landscape, but they were demoted back to B-sides, and lost the prominence acquired in the 1970s. No artist, producer or audio-engineer became as specialized in the genre as Lee Perry, King Tubby or Scientist, and less and less dedicated dub albums were released. Yet, while dub receded in Jamaica, it took root overseas. In the UK, Dennis Bovell released a series of dub albums between 1978 and 1980; Neil "Mad Professor" Fraser founded his Ariwa label in 1979; and after a first dub album in 1978, Adrian Sherwood launched his own On-USound label in 1980 (Sullivan 2014: 83). All three have remained dedicated and influential dub artists to this day. In New York, producers such as Brad Osborne, Everton Da Silva and Lloyd "Bullwackie" Barnes released a series of important dub albums in the 1970s, often in collaboration with artists from Jamaica (Sullivan 2014: 92-6). From there, dub expanded worldwide. Table 2 presents the number of dub albums referenced on Discogs, ${ }^{8}$ in the whole world and Jamaica, respectively, with Jamaica's rank for dub albums production reported in parenthesis. Even if imperfect, these figures indicate a very clear trend: since the early 1970s, dub has been prospering - but outside of Jamaica. Five hundred and twenty-one dub albums were released in the 1970s, 152 of which in Jamaica, and it is very likely that a significant proportion of US and UK albums were in fact recorded there. In the 2000s, 5,572 dub albums are referenced, more than ten times more, but only ten coming from Jamaica—less than from Hong Kong!

\begin{tabular}{|l|l|l|l|l|}
\hline $\begin{array}{l}\text { Number of } \\
\text { dub albums }\end{array}$ & $1970 \mathrm{~s}$ & $1980 \mathrm{~s}$ & $1990 \mathrm{~s}$ & $2000 \mathrm{~s}$ \\
\hline Whole world & 521 & 1,645 & 3,654 & 5,572 \\
\hline Jamaica (rank) & 152 (2nd) & $74(4$ th) & $36(14$ th) & 10 (37th) \\
\hline
\end{tabular}

TABle 2. Dub albums production

Besides its spread as a genre per se, dub has also expanded through the emergence and development of derivative and hybrid genres (such as dub poetry, digidub, dubstep and dub techno), as well as through its aesthetic and technical influence on other genres and styles. To quote Howard on Lee Perry and King Tubby:

Today, the two Jamaicans are rightly regarded as the forefathers of mixology-a beat science that has significantly influenced punk pioneers (the Clash and the Slits), post-punk deconstructionists (the Fall and Public Image Ltd.), trip-hop/jungle/drum and bass mavens (Massive Attack, Tricky and Squarepusher, et al.), turntablists (DJ Spooky and Cut Chemist), and hip-hop innovators (from Grandmaster Flash, to the Beastie Boys, to Timbaland) and beyond (2004: 230-1).

Dub may also have played a key role in the emergence of "the now commonplace practice of song remixing" (Veal 2007: 2). If dub was born in Jamaica in the early 1970s, a dozen years later it almost vanished in its native land as an autonomous genre to flourish elsewhere. How could this paradoxical evolution be possible? As dub is a progeny of Jamaican popular music, emerging in the early 1970s, the following section will discuss reasons for this formation. 


\section{The Birth Of Dub: Why Jamaica?}

\section{Music CREATEd By Jamaican Audio-Engineers}

As discussed in the previous section, and evident for its listeners, dub's characteristic trait has been the re/interpretation through mixing of recorded tracks. It was primarily crafted by audio-engineers. For example, half of the dub artists presented in Table 1 were first and foremost audio-engineers, ${ }^{9}$ even if boundaries between the roles and functions of music production have not always been easily drawn in the Jamaican context. The position of the audio engineer was at the mixing console, between musicians and vocalists on the input side, and pressed recordings on the output side. For dub to be possible, audio-engineers must have had the technical and statutory possibilities to creatively alter the recorded material before its release.

As for the technical context, it was practically impossible to make dubs in Jamaica, or anywhere else in the world, before 1963, simply because the music performers (musicians, vocalists) were recorded on a single track (Hitchins 2014: 8). Even if early recording techniques could to some extent be used creatively, mainly through the placement of microphones, it was not possible to re/interpret a set of tracks once recorded. Studio re/interpretation only became possible after 1963 with the introduction of multi-track recording consoles (Hitchins 2014: 8), which allow for the rearrangement and alteration of different musical parts. Volume, balance and timbre of the different tracks could be modified, while sound effects (delay, echo, reverb) could be used and external sounds added. The creative space for post-recording mixing steadily expanded in the 1960s and 1970s as recording studios became better equipped, shifting from the basic one-track Federal studio of Ken Khouri in 1959 to the multi-track facilities of the 1960s and the sixteen track machine installed by Byron Lee at his Dynamic Sounds studio in 1970 (O'Brien Chang and Chen 1998: 84-5). Throughout this period, Jamaican audio-engineers tended to work at the frontier of technological constraints. Engineers skilled enough to modify audio equipment-producing new sound effects—had a decisive advantage. King Tubby, with his background in electrical engineering, stood far above the others in this respect. To quote Howard:

Tubby created customized reverb machines, makeshift equalizers, and homemade delay units. His most important enhancement involved replacing the board's four worn-out sliding volume faders with newer, more resilient sliders that afforded him far greater command and control of the mixing levels. By improving the flexibility of the faders, Tubby was given a clear advantage over competing engineers (2004: 221).

Recording and mixing technology thus set, unsurprisingly, the technical conditions of possibility for dub.

However, on top of these technical possibilities, to create versions and dubs, the audioengineer must also have had the statutory capacity to alter the recorded sounds: to intervene for artistic reasons - and not merely technical ones-during the developmental process of a 
record, as in the case of Jamaican audio-engineers. Indeed, when musical production started in Jamaica in the 1950s and early 1960s, producers (such as Motta, Khouri or Seaga) knew very little if anything about the technical aspects of audio-engineering or about the tastes of the target audience, thereby allowing for an important autonomy of the audio-engineers (Hitchins 2014: 66). Likewise, musicians and vocalists were often gathered by a producer on a project-basis rather than structured as a regular band (Bradley 2001: 50; Hitchins 2014: 78). This session-based approach to music production, combined with the flexibility and impermanent nature of instrumentalists' and singers' collaboration, also tended to give audio-engineers a role of arrangers, or of creative coordinators. To quote Hitchins, Jamaican popular music production has been characterized by "an attitude towards the recording process where the audio engineer assumed responsibility for all aspects of sound creation and capture as a creative rather than technical endeavor" (2014: 70).

This technical and institutional context thus permitted the emergence of dub, but couldn't be the determining factor, as it was not specific to Jamaica. Innovative and stateof-the-art audio equipment was not used in Jamaica first, as it was created and developed in technologically advanced and industrialised economies-North America, Western Europe and Japan. As for the creative role of the audio-engineer, even if it has been specifically constitutive of the Jamaican musical milieu, it was also present in general in popular music production from the late 1960 s to the early 1970 s, when audio-engineers progressively turned from what Kealy (1979) calls the purely technical "craft-union mode" to the creative "art mode". The roles of engineers such as Geoff Emerick for the Beatles' Revolver or Sgt. Pepper's Lonely Heart Club Band (Howard 2004: 23-4, 29-30; Hitchins 2014: 215), or Mike Ross and Eddie Kramer on the "Third Stone From The Sun" track for Jimi Hendrix' Are You Experienced? album, were no less important than the ones played by Jamaican audio-engineers - the audio-engineering work on "Third Stone From The Sun" being, for example, mentioned by UK dub artist Dennis Bovell as a seminal influence (Sullivan 2014: 78). In brief, the opening of post-recording mixing possibilities, for technical and statutory reasons, made the emergence of dub possible, but as similar developments took place elsewhere, the decisive factors in the Jamaican formation of dub must also lie elsewhere.

\section{Mixing For The JAMAICAN AUdienCE}

First, versions and dubs had the same objective as Jamaican popular music in general: dancing in the dance hall-as exemplified by the aforementioned history of the first version ever played. The dance hall crowd danced to low frequencies. One of the main differences between early versions and later dubs was the emphasis, in the latter, on bass and drum (Veal 2007: 57), a feature that has remained constitutive of dub as a genre. There are two other defining characteristics of Jamaican popular music of the 1970s, which were present or even emphasized in dub mixes: syncopation and "rawness". Syncopation in this context can be traced back to ska and its emphasized afterbeat, ${ }^{10}$ which has become "the hallmark of later Jamaican music" (Barrow and Dalton 2004: 4). The second trait of Jamaican popular 
music, also inherited from its first days-from Motta's studio according to Hitchins (2014: 20)- has been the tolerance, if not a preference, for what can be called a "raw" sound, the seemingly "unsophisticated" and even "discordant" rendering of a "downtown" or "from the country" feeling (Hitchins 2014: 20; O’Brien Chang and Chen 1998: 33). ${ }^{11}$ From interviews and his own experience of the Jamaican music milieu as a session musician, Hitchins states that Jamaican popular music has been characterized by "an approach that is driven by intuitiveness and spontaneity rather than by concepts of perfection in regard to performance or sound" (2014: 20). Thus, dubs were primarily characterized by a rendering, and even an emphasis, of three traits of their musical material: low-frequency rhythms, syncopation and rawness.

Another Jamaican feature that distinguished dub from other music genres using the mixing console as a creative device is time. Jamaican musical production has been indeed characterized by an intense time pressure. Bassist George "Fully" Fulwood describes to Veal the process of 1970s studio production, how "we might go inna the studio about two hours, and come with fourteen, fifteen songs!” (2007: 47). Hitchins (2014: 78-9) similarly notes that during a typical recording session for Dodd in the 1960s, each song was allowed a maximum of three takes, whereas at the same time, a US pop record could represent 100 hours of studio time. In the 1990s, the production of a tune took approximately four to six hours (Hitchins 2014: 167). This is first and foremost due to the fact that Jamaican music producers were investors and financiers (Bradley 2001: 41; Hitchins 2014; 63-6) under acute competitive pressure: they were thus willing to craft records rapidly and efficiently. Moreover, their primary goal was to release records as "acetates" or "dub plates", shortlived soft-wax discs designed to be tested and played exclusively but temporarily by sound systems (Veal 2007: 51-2). If successful, the record could then be released commercially. This two-step commercialization process allowed or even called for a modality of music production through trial-and-error experimentation, which was made possible by the aforementioned tolerance for imperfections and mistakes. Jamaican audio-engineers and dub artists created in the same general context: they had to mix quickly, but mistakes were allowed. Lynford Anderson remembers recording and mastering "almost a hundred songs a day" (Barrow and Dalton 2004: 91), while Scientist states about his dub production that "all these albums, we did them like in hours" (Veal 2007: 47). This gave rise to a specific mode of mixing, which Hitchins (2014) labels "performance-mixing", and which is maybe best defined by Veal as "using the mixing-board as an instrument of spontaneous composition and improvisation" (2007: 78). ${ }^{12}$

Finally, in parallel with the multiplication of dubs in the 1970s, a mode of production unique to Jamaican popular music emerged: what Hitchins (2014) calls the "riddim production method" (see also O'Brien Chang and Chen 1998: 75-8; Bradley 2001: 349352; Barrow and Dalton 2004: 261; Manuel and Marshall 2006; Veal 2007: 48). Rhythmic patterns of bass and drum became autonomous from the songs they were used in. These riddims were taken from an existing song or-increasingly-"composed as autonomous music backing tracks" (Hitchins 2014: 135). Riddims became the support of numerous 
(sometimes hundreds ${ }^{13}$ ) of songs or interpretations-including versions and dubs. The riddim production method appears as articulated with the two aforementioned specificities of the Jamaican context, both linked with the centrality of the dance hall and the sound system: the intense pressure of competition; and the primary objective of dance. Indeed, on the production side, the re-use of pre-existing and popular rhythms reduced both cost and risk for the producer (Manuel and Marshall 2006: 448, Veal 2007: 55), while the riddim method also satisfied the aesthetics and selection of sound system operators. First, in a sound system, the selector acted as a "macro-composer" (Veal 2007: 85), and having at their disposal several tracks recorded on the same riddim was extremely useful in constituting sets, enabling the selector to keep the crowd dancing to an efficient rhythm pattern (Bradley 2001:333). Second, to make a difference in the fierce competition between sound systems, operators had to play specific records (called "dub plates", "specials", or "acetates"), which generated a constant demand for special mixes or versions of popular songs (Veal 2007: 53). Mixing dubs from existing tracks thus provided a convenient way for producers to offer selectors a variety of tracks to compose their sets and specific tracks to attract an audience hungry for novelty and variety. So dub was consubstantial to the emergence of the riddim production method, as it constituted a way to introduce diversified and specific interpretations of rhythmic patterns.

The available studio production techniques and the status of audio-engineers made the birth of dub possible in Jamaica in the 1970s, and this matrix was brought to fruition by the specific fertile elements of Jamaican popular music at that time, in terms of musical material, production context and consumption patterns. This explains dub's particular aesthetics (low-frequency rhythm basis, syncopation, rawness) and modality of production (performance-mixing, multifariousness of interpretations). However, while this context remained largely unchanged, dub faded from the front stage after the mid-1980s in Jamaica. The final section will argue that dub did not last as "a contemporary musical movement in Jamaica" (Veal 2007: 188) because it constitutes a transient by-product of the evolution that eventually gave birth to the dancehall genre. Yet dub has not disappeared, either: it persists on B-sides in Jamaica, and flourishes elsewhere.

\section{The Continuation Of Dub: Why Not Jamaica?}

\section{AN INTERMEDIATE PRODUCT}

As stated before, in parallel with the emergence of dub, Jamaican popular music evolved toward the riddim production method (Hitchins 2014), or the "riddim/voicing system" (Manuel and Marshall 2006). The multiplication of versions since the late 1960s, followed by dubs, was correlative to the increasing dissociation between a completed tune and the supporting track. The supporting track was the rhythm pattern plus (optionally) a melodic scheme, while the completed tune included the addition of vocals and instruments during the final studio mix. 
The re-use of existing tracks to generate new records is not specific to Jamaica: covers and versions are pervasive in popular music. However, this practice has taken hold in Jamaica at an unequaled scope, and has eventually become the very principle of music creation. In the late 1960 s, the release of the first versions constituted the first step in the deconstruction of Jamaican tunes into two elements: the rhythmic (and optionally melodic) infrastructure and the vocal/instrumental/dub interpretation, wherein a version revealed a mere exposition of the infrastructure. The second step took place in the early 1970s with the first releases of follow-up versions of existing tracks, that is to say the addition of a new superstructure on top of the versions. The significant breakthrough in this direction was undoubtedly the huge success of U-Roy, who in 1970 was celebrated for his toasting (Jamaican-style rap or public address) over versions of Duke Reid's rocksteady classics (Barrow and Dalton 2004: 123). In a few years time, Jamaican producers began re-using their rhythm tracks-or that of their competitors' hits-to record new tunes. The phenomenon steadily developed in the 1970s, with symptomatic moments like the release of Yamaha Skank (1974), the first album dedicated to interpretations of a single rhythmic infrastructure, taken from Slim Smith \& The Uniques' "My Conversation” (Barrow and Dalton 2004: 292). This evolution culminates in 1985, when Jammy released Wayne Smith's “Sleng Teng”. Indeed, Jammy first carefully worked with Noel Davy on the rhythmic infrastructure (Hitchins 2014: 107-11), completely autonomously, before any projected future interpretation. After Wayne Smith's version and its huge success, the "Sleng Teng" riddim has been used as a supporting infrastructure for nearly a hundred other tunes in 1985, to a total of several hundred up to this day. ${ }^{14}$ As Hitchins writes, the "Sleng Teng" moment "displaced the 'song' in favour of the 'riddim' as the central creative focal point" (2014: 100). The 1985 success of Sleng Teng concluded the transitional dynamics of Jamaican popular music production that had begun with Redwood's first version in 1967 . The rhythm track-now called riddim-became fully acknowledged as an infrastructure available to support numerous interpretations.

Dub constituted a dimension of this structural evolution of Jamaican popular music between 1967 and 1985, parallel to the multiplication of vocal, DJ or instrumental interpretations of the existing rhythmic infrastructure. But there is an essential difference between dubs and these three other kinds of versions. The vocal and instrumental versions constituted finished, yet open, musical products that could be played by the sound system as they were, and took the rhythmic infrastructure as given. On the contrary, dub versions worked on the rhythm tracks themselves: they went deeper into the reinterpretation of existing rhythmic infrastructures. At the same time, they remained unfinished and incomplete in the Jamaican context, for they were designed to support a superstructure: the vocals, and especially the live toasting of a DJ, as performed by the sound system primarily and on record occasionally. ${ }^{15}$ Indeed, vocals and lyrics have been a constitutive dimension of the process of cultural creation that takes place in the dance hall and through the sound system, with the DJ playing a fundamental role. As Cooper writes, "pleasure in the word is a fundamental element of the total theater of the dancehall" (2004: 5). Jamaican 
sound system culture thus has had a constitutive literary dimension, even if an oral one, making it what Devonish (1998) calls an "orature". Whereas vocal, DJ or instrumental versions showed how an existing rhythmic infrastructure could be re-used to generate several musical finished products, dubs manifested how this rhythmic infrastructure could be interpreted and modified to provide support for new versions. While the first versions separated recorded songs from their rhythmic infrastructures, vocal/DJ/instrumental and dub versions constituted a shift in the general evolution of Jamaican popular music toward the riddim production method: the former leading to the multiplication of records on the same rhythm tracks, the latter to creative work on the same rhythmic pattern.

Versions and dubs thus mostly remained an intermediate material for the production of vocal, DJ or instrumental tunes. For example, despite the huge amount of versions and dubs released at the time, only a handful appear in the whole series of yearly top 25 records of Jamaican charts for the years 1970 to 1985 (as noted by O'Brien Chang and Chen, 1998: 224-8). This underscores that dub, for the Jamaican popular music mainstream, remained an unfinished musical product, waiting to become the support of an interpretation-for a record or in the dance hall. However, this particularly intermediate position of dub versions became less and less tenable in the early 1980s, with technological developments in soundrecording techniques and the settling of the riddim production method.

\section{Dub Grows Up InTO DANCEHALL}

As depicted, the re-use of existing rhythm tracks led progressively to the differentiation of Jamaican music production in two steps: the building of generic riddims, and their subsequent use as a support for various tunes. The creation of rhythmic infrastructures has come to replace the reinterpretation of rhythm tracks extracted from existing songs. This structural evolution of Jamaican popular music was reinforced, if not made possible, by technological change. Indeed, during the 1970s, dubs were often mixed by audio-engineers from musical material that was pre-recorded, on which they had little control, if none at all. For example, King Tubby's studio was too small to record live musicians, so Tubby and his acolytes (in particular Scientist and Jammy) had to work on pre-existing tracks, recorded by others. This context radically changed in the 1980s, due to the diffusion of new music technologies, especially drum machines and synthesizers (Hitchins 2014). With the new technologies, it became possible for audio-engineers to create novel tracks and sounds, as they did not have to rely solely-if at all —on prerecorded material. Even if studio musicians remained in high demand, the fact that they could now be recorded one at a time on a multitrack system, rather than as a group, reinforced the direction and creative role of the audio-engineer. As a consequence, the dub practitioners and audio-engineers of the 1980s could go one level deeper in their composition of rhythmic infrastructure. In the dub versions of the 1970s, audio-engineers interpreted and rearranged rhythmic structures taken from existing songs; with the technological developments of the 1980s, they could now directly build riddims from scratch. 
At the same time, these new techniques also permitted a closer connection between the composer of the supporting rhythmic infrastructure and the DJs or singers who "ride it", as the expression goes. Indeed, the advent of multitrack recording technology allowed studio engineers to easily record, one after the other, several vocalists (or instrumentalists) over the same rhythm structure. The recording engineer could even alter or modify the supporting rhythm (and other) tracks to suit different vocal interpretations. Based in particular on his own experience as a session musician in Jamaica, Hitchins writes: "performance-mixing therefore employed dub and version B-side mixing strategies but applied them in a new role, helping to integrate multiple vocal performances with a pre-recorded riddim as cohesive pieces of commercial music" (2014: 139).

In the 1980s, technical changes as well as the general spread of the riddim production method extended dub's intermediary role. If dub seemed to lose prominence in Jamaican popular music production, it is because it expanded, upstream and downstream, deeper into rhythmic composition, and further into the adaptation of the eventual vocal interpretation. Dub "grew up" into the riddim-production method, characteristic of the dancehall sound, the dominant genre of Jamaican popular music after 1982. The traits attached to dub were thereby transferred to riddim-based dancehall. The primacy of the rhythm, at the service of vocal interpretations, the importance of sonic experiments and musical innovations, and, finally - a characteristic feature of contemporary Jamaican popular music production - the practice of performance-mixing that are all common to dancehall all derive directly from dub. If dub ceased to be a primary focus of the musical production in Jamaica, it is because dub's constitutive set of techniques evolved together with the available technology. Dub was eventually absorbed into the new genre of dancehall, with its own musical material.

Perhaps the best illustration of this absorption of dub into dancehall is the trajectory of King Tubby and his apprentice Jammy. Both represented the intermediary status of dub productions in the 1970s. As noted previously, at Tubby's studio, they didn't have room to record musicians, so they mixed tracks recorded elsewhere (Veal 2007: 116). But they also seized any opportunity to expand their creative control, upstream and downstream. Eventually, a vocal booth was set up (Sullivan 2014: 46). Significantly, though, Jammy came to signify the shift of Jamaican music into computerized, riddim-driven dancehall with the release of the epoch-making hit Under Me Sleng Teng by Wayne Smith in 1985. Trained as an audio-engineer by Tubby, Jammy became the "undisputed ruler" of early digital dancehall (Barrow and Dalton 2004: 291), while Tubby soon joined this new sound (Barrow and Dalton 2004: 303-5). Representing Jamaican dub in general in the 1970s, the production work of Tubby and Jammy created, and developed, the popular music genre of dancehall in the 1980 s.

\section{Dub's Seminal Versatility}

Dub receded in Jamaica as an autonomous and significant genre during the mid-1980s, when its techniques and objectives became constitutive dimensions of the new dominant sound, dancehall. However, if this evolution may have been unavoidable in the Jamaican context, 
with its specific aesthetic and production values, outside of Jamaica dub has survived as a distinct genre; it has generated, alone or through hybridization, many subsequent genres, and it has influenced popular music in general. Indeed, its transitional, experimental and exploratory nature makes dub a multifaceted and shifting object, of which boundaries are not readily drawn, and definitions are not easily specified. Yet this ambiguity makes it especially seminal. Dubs may be the ancestors of remixes, now pervasive in popular music (Veal 2007:2). Dub's riddim aesthetic, based on the sounds and culture of the roots reggae era, have provided the conditions for the musical genre of dub poetry (Moskowitz 2006: 94). Although many dub progenies could be identified and debated, I wish to conclude by discussing why it is outside Jamaica that dub has developed as a stand-alone genre.

As depicted earlier, despite their significance for Jamaican music in the 1970s, dubs basically constituted intermediary products between the pre-recorded tracks and vocals. Outside of Jamaica, however, dub met listeners who were not necessarily dancehall participants. This international audience did not expect dubs to be danced to and/or to be interpreted through toasting. They could have been exposed to other genres-in particular psychedelic rock and funk, but also disco, house, techno and hip-hop-that also relied on the creative use of the mixing console. The global audience of the "dub diaspora" tended to take dubs as finished products, with specific listening and aesthetic characteristics. As Adrian Sherwood, a pivotal UK dub artist since the late 1970s, states: "we all loved reggae, but when the dub stuff came along it was just perfect for sitting down and listening to and getting blasted" (Sullivan 2014: 88). Even if this disposition also existed in Jamaica, it was more prevalent overseas. For example, the aforementioned initiative to release the single "Baby I Love You So" with the dub "King Tubby Meets Rockers Uptown" on the A-side came from the US Mango and UK Island labels (Bradley 2001: 323), whereas in Jamaica, the dub version remained on the B-side. ${ }^{16}$ The fact that most of Scientist's albums (or compilations) were released under international labels such as Greensleeves or Clocktower, even before Scientist left Jamaica ${ }^{17}$ illustrates that albums produced by Jamaican artists and specifically dedicated to dub as a genre were often-if not most often-aimed at foreign buyers. The identification and delineation of dub as a discrete genre are thus-at least partly-predicated on the way it was received by listeners outside of Jamaica (Veal 2007: 224).

Probably the clearest illustration of this difference between the overseas and Jamaican use and understanding of dub is the contrast between Lee Perry and King Tubby's respective trajectories, as the two undisputed Jamaican dub masters stood exactly at opposite poles of the Jamaican dub world. It is true of their personalities; Tubby's always shiny shoes and sobriety stood in stark contrast to Lee Perry's consumption of alcohol and drugs and extravagant behavior. More importantly, this contrast is true in their approach to dub. Indeed, Tubby's studio was conceived to mix material that had been recorded elsewhere, and the intended output was B-sides as well as dubplates, specials or acetates, whereas Lee Perry's Black Ark studio, founded in 1974, was fully equipped to record musicians and vocalists. So while Tubby's dubs were by essence intermediary musical products, and so represented the quintessence of the place of dub within the general Jamaican music production, Lee Perry, on the other hand, created complete musical products. Perry's productions began not with 
a rework, but with recording studio musicians. Perry went through the intermediate steps of performance and experimental mixing to the eventual additions of vocals and the final mix. His dubs were finished, stand-alone tracks, as discussed earlier through the example of his Super Ape album. As Sullivan summarizes:

Although both Perry and Tubby are of equal stature in the history of dub, their working methods were completely different. Tubby worked with a mixing board and vocals, while Perry constantly worked on live rhythms and compositions (in fact, his sessions often started off with recording the studio band). Tubby "stripped down", whereas Perry's approach was often more additive (2014: 48).

With their respective interpretations of dub techniques and aesthetics, King Tubby always remained at the very core of the Jamaican music mainstream, with limited outside influence, while Lee Perry found himself increasingly on the fringes in Jamaica, with a growing audience overseas. After scoring a few hits in the UK at the end of the 1960s, and through an arrangement with the newly founded UK-based Trojan Records, Perry "made the first of many trips to London in 1969" (Katz 2006: 80), while at the same time he shifted his production towards instrumentals and experimentation (Katz 2006: 81-3). By the end of the 1970s, Perry was heavily dependent on the UK Island label for the release and promotion of his production, which was less and less present in Jamaican dance halls. As Katz writes, "Perry's link with Island had given him the greatest exposure outside Jamaica, helping to establish him as a cult figure with an entirely new audience" (2006: 302). Lee's productions in Jamaica, at the close of the 1970s, "are complex and dense experimental works on which Perry's individual personality is strongly evident, equally indicative of how far his creations were from reggae's mainstream" (Katz 2006: 301). Eventually, in the early 1980s, the Black Ark studio was destroyed by fire, and Perry left Jamaica to continue his still-ongoing musical career overseas.

The paths of King Tubby and Lee Perry represent dub's dual destiny. Tubby remained faithful to dub's origins-mixing versions - and eventually shifted to riddim-based and digital dancehall, thus exemplifying the place and trajectory of dub within the Jamaican music mainstream. On the other hand, Perry expanded dub techniques and aesthetics to develop it as a genre, progressively growing apart from the Jamaican dance hall public, but establishing contact with an overseas audience. If the versioning or remix dimension of dub, as represented by Tubby's approach, was eventually absorbed into the very production of Jamaican music after the mid-1980s, dub was received as a genre per se by different publics overseas, and, as represented by Lee Perry, it is abroad that it eventually found the context to endure and develop.

\section{CONCLUSION}

Dub appeared in Jamaica in the early 1970s, occupying the creative space opened by versions between recorded tracks (especially their rhythmic infrastructures) and their interpretations in sound system performance (mainly in DJ toasting). Up until the mid- 
1980s, dub developed as a part of Jamaican popular music, shifting toward a specific modality of creation, the riddim production method, where riddims are built to support several vocal interpretations. Dubs constituted by-products of this evolution, but necessary ones, as dub as a sub-genre represented the laboratory where techniques and aesthetics of rhythm construction and interpretation were elaborated. As these newer riddim techniques became established, Jamaican dub lost its raison dêtre, and the set of techniques it embodied was absorbed into dancehall. King Tubby's trajectory epitomizes this mainstream dynamic. However, outside Jamaica, dubs were also received as stand-alone musical works, with a decisive influence on popular music, especially through dub's specific mixing strategies and objectives. As with Lee Perry himself, who stepped out of Jamaica's musical context, dub has developed independently - to become a genre full of life with numerous global offspring.

\section{ACKNOWLEDGEMENTS}

I would like to thank Jedediah Sklower for his support and Audrey Bangou for her advice on earlier versions of this manuscript, as well as tobias c. van Veen and Hillegonda Rietveld for their careful reading of this paper, and their valuable comments. I must also acknowledge the important feedback from an anonymous reviewer.

\section{NOTES}

1 The term DJ has a specific meaning in Jamaica: the selecta (selector) plays in a Jamaican sound system the role of what is called a DJ elsewhere; in other words, they are the person who selects the tracks, while the $D J$ is a MC (master of ceremonies), a vocalist who toasts (raps) on the music that is being played (Stolzoff 2000: 98).

2 While the syncopated feelings of Jamaican popular music (or of other music genres for that matter) are often attributed to the emphasis on the offbeat, this term itself has no standard definition, and can actually cover several diverging meanings. "Off" beats can first be understood as the opposite of the "on" beats, that is to say the strongest beats in a standard $4 / 4$ measure, beat 1 being the strongest one (the "downbeat"), beat 3 the second strongest. Offbeat is thus very often taken simply as a synonym of "backbeat", which is strictly defined as the second and fourth beat of a $4 / 4$ measure. But offbeat can also be understood as "upbeat", that is to say, a sound that takes place between beats. In the context of Jamaican popular music (and African music), these upbeats are called "afterbeats", because they tend to echo or delay the preceding beat-rather than anticipating the following one (for a detailed discussion, see McCarthy 2007: 64-7). As a matter of fact, Jamaican popular music is characterized by both dimensions of the "offbeat", as it combines "accented afterbeats with heavy backbeats" (Witmer and McCarthy 2014: 653).

3 Version is written in italics thereafter when referring to the specific musical product it denotes in Jamaica. 
4 The whole single, with the vocal on the A-side and the dub version on the B-side can be listened to at: $<$ https://www.youtube.com/watch?v=85tDl9gtSnQ> (accessed 30 September 2015).

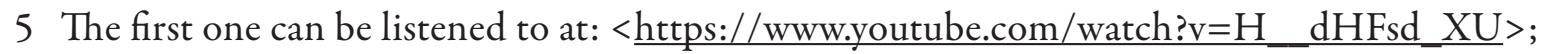
the second at: $<$ https://www.youtube.com/watch?v=-UY5cNmY0BA $>$ (both accessed 30 September 2015).

6 Table 1 does not aim to be exhaustive, but, rather, provides synthetic insight on the most active and significant artists, audio-engineers and producers of dub in Jamaica. The information presented comes from reference works on Jamaican popular music (especially O’Brien Chang and Chen 1998; Bradley 2001; Barrow and Dalton 2004; Moskowitz 2006; Veal 2007), and from online databases (Discogs, riddimguide and roots-archives).

7 These are the results of a search carried out on Discogs, with three filters: dub as style, LP as format, and Jamaica as country: <http://www.discogs.com/search/?style

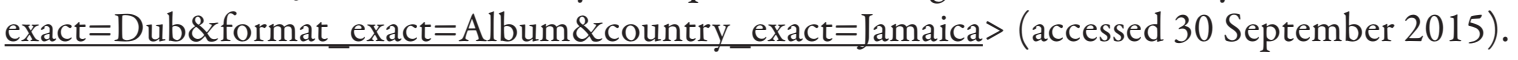

8 Research conducted on Discogs for albums labelled as related to the dub style < http://www. discogs.com/search/?style_exact=Dub\&format_exact=Album $>$ (accessed 30 September 2015).

9 Namely: Errol Thompson, King Tubby, Lyndord Anderson, Peter Chemist, Prince/King Jammy, Scientist and Sylvan Morris.

10 See Note 2.

11 Among many others, an illustration of the difference between the sonic values in Jamaica and for the more general popular music world can be found in the comparison between the track "Love One Another" by Althea \& Donna in 1978 (prod. Joe Gibbs) and its re-mastered version (under the title "Jah Rastafari") for the 2001 re-release of their album Uptown Top Ranking, which can be respectively listened to at <https://www.youtube.com/ watch? $=$ X 5xNXh414OA $>$ and $<$ https://www.youtube.com/watch? $\mathrm{v}=$ sWBE0gk5NMA $>$ (both accessed 30 September 2015).

12 A clear illustration of the practice of "performance mixing" is the video of Prince Jammy mixing the dub "Jailhouse Rock" in the documentary Deep Roots 2: Bunny Lee Story/Black Ark (Part 3-Bunny Lee Story, approx. 44:53-46:30), and viewable online at: <https://www. youtube.com/watch?v=s-KsWcv6YnM> (accessed 30 September 2015).

13 The Top 10 riddims according to Riddimguide: <http://www.riddimguide.com/more/ statistics $>$ (accessed 30 September 2015).

14 See Riddimguide: <http://www.riddimguide.com/tunedb/riddim_Sleng\%20Teng/sortby year> (accessed 30 September 2015).

15 A sequence "song - dub - DJ" can be found on the Phil Pratt Thing compilation, with "Going The Wrong Way" by Al Campbell, the discomix (dub) and its interpretation by Big Youth, "Love Jah Jah Children".

16 See the Discogs summary of Jamaican releases <http://www.discogs.com/Jacob-Miller-Baby-ILove-You-So/release/862755 > compared with international ones < http://www.discogs.com/ Augustus-Pablo-King-Tubby-Meets-The-Rockers-Uptown/release/1891051> (both accessed 30 September 2015).

17 See Scientist's albums referenced on Discogs (< http://www.discogs.com/artist/33468$\underline{\text { Scientist?type }=\text { Releases }>}$ ) (accessed 30 September 2015). 


\section{REFERENCES}

Barrow, Steve and Peter Dalton. 2004. The Rough Guide to Reggae. $3^{\text {rd }}$ ed. London: Rough Guides Ltd. Bradley, Lloyd. 2001. Bass Culture: When Reggae Was King. London: Penguin Books. Cooper, Carolyn. 2004. Sound Clash: Jamaican Culture At Large. New York: Palgrave MacMillan. Devonish, Hubert. 1998. "Electronic Orature: The Deejay's Discovery". Social and Economic Studies 47(1): 33-53.

Henriques, Julian. 2003. "Sonic Dominance and the Reggae Sound System Session”. In The Auditory Culture Reader, ed. Michael Bull and Les Back, 451-80. Oxford: Berg.

Hitchins, Ray. 2014. Vibe Merchants: The Sound Creators of Jamaican Popular Music. Farnham: Ashgate Publishing.

Howard, David N. 2004. Sonic Alchemy: Visionary Music Producers and Their Maverick Recordings. Milwaukee: Hal Leonard Corporation.

Katz, David. 2006. People Funny Boy: The Genius of Lee Scratch Perry. London: Omnibus Press.

Kealy, Edward R. 1979. "From Craft to Art: The Case of Sound Mixers and Popular Music". Work and Occupations 6(1):3-29. <http://dx.doi.org/10.1177/009392857961001>.

Manuel, Peter and Wayne Marshall. 2006. "The Riddim Method: Aesthetics, Practice and Ownership in Jamaican Dancehall”. Popular Music 25(3): 447-70. $<$ http://dx.doi.org/10.1017/S0261143006000997>.

McCarthy, Leonard J. 2007. "The Significance of Corporeal Factors and Choreographic Rhythms in Jamaican Popular Music Between 1957-1981 (Ska, Rocksteady, Reggae), With an Historical and Critical Survey of all Relevant Literature Dealing with Jamaican Folk, Religious and Popular Musics and Dance". PhD. Dissertation (Higher Education), York University.

Moskowitz, David V. 2006. Caribbean Popular Music: An Encyclopedia of Reggae, Mento, Ska, Rock Steady, and Dancehall. Westport: Greenwood Press.

O'Brien Chang, Kevin and Wayne Chen. 1998. Reggae Routes: The Story of Jamaican Music. Philadelphia: Temple University Press.

Stolzoff, Norman C. 2000. Wake The Town \& Tell The People: Dancehall Culture in Jamaica. Durham: Duke University Press.

Sullivan, Paul. 2014. Remixology: Tracing the Dub Diaspora. London: Reaktion Books.

Veal, Michael. 2007. Dub: Soundscapes and Shattered Songs in Jamaican Reggae. Middletown: Wesleyan University Press.

Witmer, Robert and Len McCarthy. 2014. "Reggae". In Bloomsbury Encyclopedia of Popular Music of the World, Volume 9, ed. John Shepherd and David Horn, 650-69. London: Bloomsbury Academic.

\section{DISCOGRAPHY}

Althea \& Donna. 1978. Love One Another. Joe Gibbs Record Globe (7-inch). $<$ http://www.discogs.com/Althia-Donna-Love-One-Another/release/3964809>.

Althea \& Donna. 2001. Uptown Top Ranking. Front Line Records (LP reissue): FL 14. $<$ http://www.discogs.com/Althea-Donna-Uptown-Top-Ranking/release/519469>.

Andy, Horace. 1972. Skylarking. Bongo Man (7-inch). $<$ http://www.discogs.com/Horace-Andy-Skylarking/release/1306560>. 
Andy, Horace. 1977. Skylarking. Jackpot (7-inch). <http://www.discogs.com/Horace-Andy-Skylarking/release/6575435>.

Beatles, The. 1966. Revolver. Parlophone (LP): PCS 7009. <http://www.discogs.com/Beatles-Revolver/release/409199>.

Beatles, The. 1967. Sgt. Pepper's Lonely Heart Club Band. Parlophone (LP): PMC 7027. <http://www.discogs.com/Beatles-Sgt-Peppers-Lonely-Hearts-Club-Band/release/499497>.

Chin, Clive, Vincent Chin and Errol Thompson. 1973. Java Java Java Java. Impact! (LP): IMP/ LP 0001 . < http://www.discogs.com/Impact-All-Stars-Java-Java-Java-Java/release/3003757>.

Chin-Loy, Herman. 1971. Aquarius Dub. Aquarius (LP): AQLP001. <http://www.discogs.com/Herman-Chin-Loy-Aquarius-Dub/release/5176419 >.

Hippie Boys, The. 1971. Voo-Doo. Syndicate (7-inch). < http://www.discogs.com/Little-Roy-Hard-Fighter/release/3360987> (UK release).

Jimi Hendrix Experience, The. 1967. Are You Experienced. Track Records (LP): 612001. <http://www.discogs.com/Jimi-Hendrix-Experience-Are-You-Experienced/release/993028>.

Maytals, The. 1968. Do The Reggay. Pyramid (7-inch): PYR-6057. <http://www.discogs.com/Maytals-Do-The-Reggay/release/3467392>.

Pablo, Augustus. 1975. King Tubby Meets The Rockers Uptown. Island Records (7-inch): WIP.6226. <http://www.discogs.com/ Augustus-Pablo-King-Tubby-Meets-The-Rockers-Uptown/release/1891051>.

Perry, Lee "Scratch" and The Upsetters. 1976. Scratch, The Super Ape. Upsetter (LP). $<$ http://www.discogs.com/Upsetters-Scratch-The-Super-Ape/release/5039060>.

Prince Buster. 1972. The Message Dubwise. Fab (LP): MS7. <http://www.discogs.com/Prince-Buster-The-Message-Dub-Wise/release/4164965>.

Scientist. 1982. Scientist Encounters Pac-man. Greensleeves (LP): GREL 46. <http://www.discogs.com/Scientist-Scientist-Encounters-Pac-Man/release/155366>.

Smith, Slim and The Uniques. My Conversation. Jackpot (7-inch): JPR 7001. <http://www.discogs.com/Uniques-My-Conversation/release/3598581>.

Smith, Wayne. 1985. Under Me Sleng Teng. Jammy's Records (7-inch). <http://www.discogs.com/Wayne-Smith-Under-Me-Sleng-Teng/release/4110749>.

Upsetters, The. 1973. Blackboard Jungle Dub. Upsetter (LP): LP 0115. <http://www.discogs.com/Upsetters-Blackboard-Jungle-Dub/release/757561 >.

Various. 1974. Yamaha Skank. Success Records Ltd. (LP): SRL LP 015. <http://www.discogs.com/Various-Yamaha-Skank/release/3886042>.

Various. 2000. Phil Pratt Thing. Pressure Sounds (CD): PSCD 27. <http://www.discogs.com/Various-Phil-Pratt-Thing/release/2050123 >.

Various. 2012. Dub Is Eternal. DubKraft Records (digital). $<$ http://dubkraftrecords.tumblr.com/post/21729335927/dub-is-eternal-the-420-dubkraft-anthology >

FILMOGRAPHY

Screenedge. 2007. Deep Roots Music 2: Bunny Lee Story/Black Ark. USA: MVD Visual. 